\title{
Evaluation of material friction properties using the "Block-on-Ring" apparatus
}

\author{
M. Kašparová, F. Zahálka \& Š. Houdková \\ Department of Thermal Spraying, ŠKODA VÝZKUM Ltd., \\ Czech Republic
}

\begin{abstract}
One of the tribological tests for the evaluation of friction properties is introduced in this paper. The test, named "Block-on-Ring", is in accordance with the standard ASTM G-77 and in ŠKODA VÝZKUM Ltd. is realized on the VRS-3 renovated apparatus. The measurement is as follows: the flat surface of the sample is pressed against the cylindrical surface of a rotating wheel of the rotor material. Arbitrary oil is fed to the material contact surface and the increasing temperature is detected using a thermocouple. The friction force is recorded using the strain-gauge dynamometer. The test is performed in a number of periods and always after one expiration time the wear track formed in the sample is measured and evaluated. The final results are the summary of the partial results of the long-standing tests and are used for the preliminary detection of the friction behavior of individual material couples.
\end{abstract}

Keywords: friction force, coefficient of friction, block-on-ring, ASTM G-77, wear.

\section{Introduction}

Friction properties rank among many important material properties, which characterize the tribological behavior of materials that are in a sliding contact. Because of the sliding between two or more machine parts friction arises. Friction is the resistance to motion during sliding or rolling what occurs when one solid body moves tangentially over another one with which it is in contact. Then, the resistive tangential force, which acts in a direction directly opposite to the direction of motion, is called the friction force. There are two main types of friction: dry friction and fluid friction. If the solid bodies are loaded together and 
a tangential force is applied, the value of the tangential force that is required to initiate the motion is the static friction force. It may take a few milliseconds before the relative motion is initiated at the interface. The tangential force required to maintain the relative motion is known as the kinetic or dynamic friction force. The static friction force is higher than the kinetic friction force, as Bhushan [1] showed. The science called "tribology" deals with the main friction problems. A large part of tribology science solves the following questions: surfaces interface, adhesive wear and lubrication of machine units. It is evident that in addition to the friction, wear also occurs. Vocel et al. [2] mentioned that friction without wear may occur if the hydrodynamic lubrication of function surfaces occurs and the compact lubricant layer is spread between two contact bodies. Friction and friction characteristics are advantageously measured using laboratory tribo-tests. Complete tests are described in the related Standards. For example, the pin-on-disc test is specified in the ASTM G-99 [3], the block-onring test in the ASTM G-77 [4], the four-ball test in the ASTM D5183-95 [5] and in the ASTM D4172-94 [6], etc.
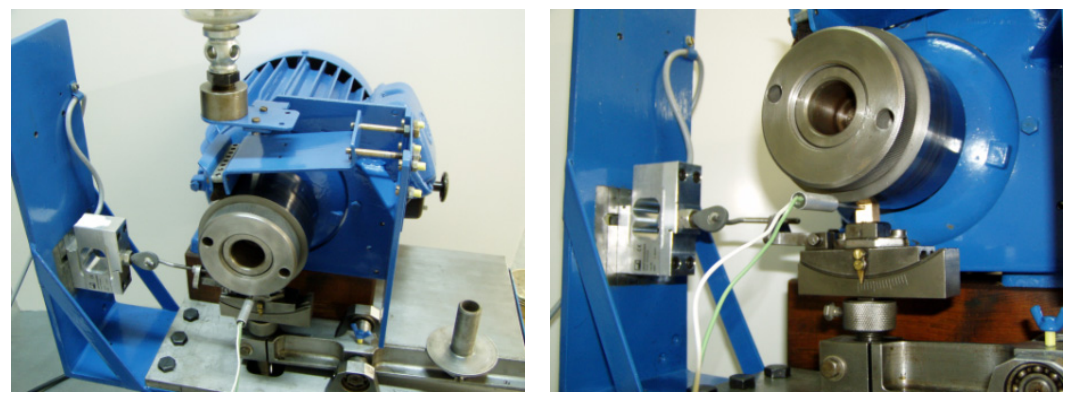

Figure 1: Block-on-ring method, VRS-3 apparatus.

\section{Experimental}

\section{1 "Block-on-Ring" method}

In ŠKODA VÝZKUM Ltd. the friction properties are evaluated using the "Block-on-Ring" apparatus, see fig.1. This apparatus, called VRS-3, was put out of operation for a long time but at present it has been renovated and it is used for the evaluation of the material friction properties. The apparatus development is described in the company annual reports [7-9]. The test is generally characterized in such a way that against the flat surface of the sample (block) the cylindrical surface of the rotating wheel of the rotor material (ring) is pressed. Arbitrary oil is fed to the material contact surfaces and increasing temperature is detected there using the thermocouple. The friction force is recorded using the strain-gauge dynamometer. The test can run in a number of periods and always after one expiration time the wear track formed in the block-sample is measured and evaluated. One of the disadvantages of this apparatus is the constant velocity of the ring sample. Because of that it is impossible to change the speed of the ring rotation and to record the statistic coefficient of friction. 
By means of the renovated apparatus it is possible to measure a dynamic friction coefficient in lubricated conditions, thermal changes in the material contacts, the wear coefficient, the actual load of a sliding couple in the contact surfaces and it is possible to monitor the waveform of the friction force during the test running. To determine the coefficient of friction, eqn (1) in [4] is used:

$$
f=\frac{F_{t}}{F_{n}}
$$

and after substitution to eqn (1), according to $[7,8]$ :

$$
f=\frac{F t}{\left(\frac{m^{*} g^{*} b}{a}\right)+k}
$$

where:

$\mathrm{Ft}$ is the friction force in the contact surface $[\mathrm{N}]$

$\mathrm{F}_{\mathrm{n}}$ is the normal force in the contact surface $[\mathrm{N}]$

$\mathrm{m}$ is load $[\mathrm{kg}]$

g is acceleration of gravity $\left[\mathrm{m} / \mathrm{s}^{2}\right]$

$\mathrm{a}, \mathrm{b}$ is the length of the laver arm [m]

$\mathrm{k} \quad$ is the constant of the measuring apparatus [-]

The technical parameters of the apparatus are listed in table 1 . The actual load is determined using eqn (3) according to [7]:

$$
G=\frac{F_{n}}{S \phi}
$$

where:

$\mathrm{G}$ is actual load [MPa]

$\mathrm{S}_{\varnothing} \quad$ is the "average" surface of the wear scar $\left[\mathrm{mm}^{2}\right]$

Table 1: Technical parameters of the VRS-3 apparatus.

\begin{tabular}{|l|l|}
\hline Engine revolutions & $1400[\mathrm{r} / \mathrm{min}]$ \\
\hline Circumferential speed & $7,33[\mathrm{~m} / \mathrm{sec}]$ \\
\hline Service voltage & $380 / 220 \mathrm{~V} ; 50 \mathrm{~Hz}$ \\
\hline Total power & $0,85 \mathrm{~kW}$ \\
\hline
\end{tabular}

For the experiment, the nominal load 3,5 MPa of the tested samples and 500 $\mathrm{km}$ sliding distance was used. The total distance was divided into six cycles. The first cycle was the running-up step and its length was one kilometer. Each of the further five steps was one-hundred kilometers long. To determine the wear coefficient of the block sample, eqn (4) was used according to [7]:

$$
k=\frac{V_{m}}{G}
$$

where:

$\mathrm{k} \quad$ is the wear coefficient $\left[\mathrm{mm}^{3} / \mathrm{km} . \mathrm{MPa}\right]$

$V_{m} \quad$ is the volume loss of the block sample $\left[\mathrm{mm}^{3}\right]$ 
For the determination of the volume loss of the block sample, eqn (5), which is stated in ASTM G-77 [4], is used (fig.2). The scar width is normally measured by the magnifying glass with an accuracy of measurement of $0,1 \mathrm{~mm}$, using light microscopy (for small widths of the wear scars) or using the profilometer "Mitutoyo SJ-201P" by measuring the profile of the wear scars (fig.3).

$$
V=\frac{D^{2} * t}{8}(\theta-\sin \theta)
$$

where:

$\mathrm{t} \quad$ is the block width [mm]

$\mathrm{r} \quad$ is the radius of the ring [mm]

$\mathrm{D} \quad=2 \mathrm{r}=$ diameter of the ring $[\mathrm{mm}]$

$\mathrm{b} \quad$ is the average scar width [mm]

$\theta \quad$ is the sector angle in radians

$\mathrm{d} \quad$ is the scar depth [mm]

As a result, eqn (5) can be written as follows:

$$
V=\frac{D^{2} * t}{8}\left[2 \sin ^{-1} \frac{b}{D}-\sin \left(2 \sin ^{-1} \frac{b}{D}\right)\right]
$$

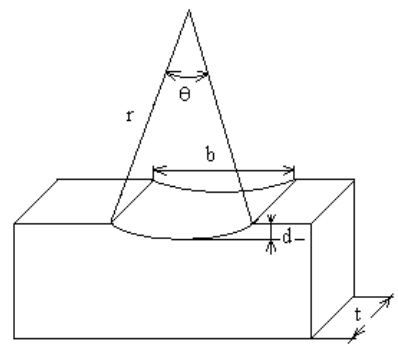

Figure 2: $\quad$ Schematic diagram of the volume loss of the block sample [4].

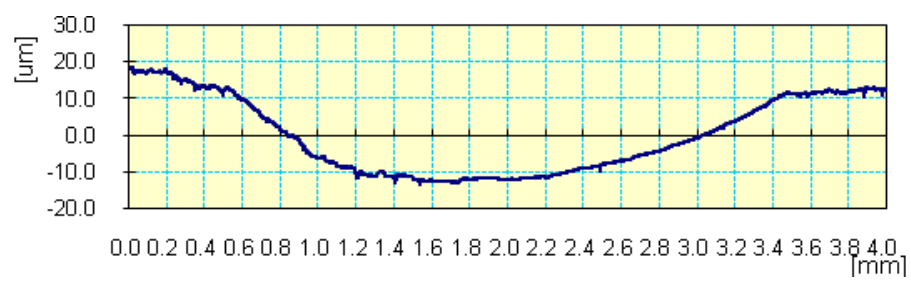

Figure 3: $\quad$ The wear scar profile.

\subsection{Experimental material}

For the experimental measurement using VRS-3 apparatus two samples of the thermally sprayed coatings were chosen: one kind of cermet coating on the base of WC-carbide (further in the text sample A only) and one kind of self-fluxing alloy on the base of $\mathrm{NiCr}$ (further in the text sample B only). The WC-base 
coatings are commonly used as a protector against different types of wear up to approx. $500^{\circ} \mathrm{C}$. The NiCr-alloys coatings are characterized by good corrosion and wear properties and they are serviceable up to approx. $850^{\circ} \mathrm{C}$. Surface hardness of the WC-sample is $67 \mathrm{HRC}$ and of the NiCr-sample is $57 \mathrm{HRC}$. These both coatings were thermally sprayed by high pressure high velocity oxygen fuel systems in ŠKODA VÝZKUM Ltd., Pilsen, CZ. The used spray parameters are the intellectual property of the company. The coatings were deposited on the test ring pieces of EN 10025-90 low-carbon steel. As the block the "stanit" tin-based babbitt was chosen. The "stanit" tin-based babbitt is one of many kinds of tincompositions on the base $\mathrm{Sn}-\mathrm{Sb}-\mathrm{Cu}$. Its chemical composition is given in table 2 .

Table 2: Chemical composition of the "stanit" tin-based Babbitt.

\begin{tabular}{|c|c|c|c|c|c|}
\hline \multirow{2}{*}{ Stanit } & $\mathrm{Sb} \mathrm{( \% )}$ & $\mathrm{Cu}(\%)$ & $\mathrm{Ni}(\%)$ & $\mathrm{Pb}(\%)$ & $\mathrm{Sn}(\%)$ \\
\cline { 2 - 6 } & $9-11$ & $2-4$ & $0,4-1,0$ & $\max .1$ & $84,5-86,5+0,5-1,1 \mathrm{Cd}$ \\
\hline
\end{tabular}

Table 3: $\quad$ Surface roughness of sample A, sample B and the stanit.

\begin{tabular}{|c|c|c|c|}
\hline Material & Sample A & Sample B & Stanit \\
\hline $\mathrm{Ra}[\mu \mathrm{m}]$ & $1,10 \mathrm{E}-01 \pm 1,55 \mathrm{E}-02$ & $2,84 \mathrm{E}-01 \pm 2,07 \mathrm{E}-02$ & $3,20 \mathrm{E}-01 \pm 5,00 \mathrm{E}-02$ \\
\hline
\end{tabular}

\subsection{Surface roughness}

Tribological characteristics depend on the surface roughness of the sliding materials. If the comparing tests between several different materials are required it is preferable to compare sliding couples of the same surface roughness. The surface roughness was measured using SJ-201P Surftester and the Ra parameter was measured. The results are summarized in table 3 .

\subsection{Lubricants}

The "Block-on-Ring" method facilitates to use many kinds of lubricants in a fluid stage. The lubricants, mostly oils, are injected into the surface contact of the samples (for the VRS-3 apparatus the lubricant presence is essential because it is not constructed for measuring in dry friction conditions). Oils include natural organics consisting of animal fat, vegetable oils, mineral fractions, synthetic organics and mixtures of two or more of these materials. It is mentioned in [1] that the main aim of the lubricants is the decreasing in friction losses, wear and noise level and increasing in absorbing and corrosive resistance. Currently in the industrial market many types of liquid lubricants are offered. From this large offer it is necessary to select the suitable lubricant for the practical application where moving parts with a sliding contact will work. Main tribological components in practical applications are e.g.: bearings, seals, cams, piston rings, electrical brushes, cutting and forming tools, etc. For the experiment the turbine deeply refined TSA 32 oil (in accordance with the ISO 6743 Standard) was chosen. This oil is characterized by the outstanding oxidative stability and antirust performance to protect turbines from rust and corrosion in 
severe conditions. It is suitable for steam turbines and water turbines, pumps and valves. The viscosity of the lubricant at temperature $40^{\circ} \mathrm{C}$ is $28,8-35,2 \mathrm{~mm}^{2} / \mathrm{sec}$. The thermal stability and its using are possible up to temperature $140^{\circ} \mathrm{C}$. During the experiments the lubricant supply to the sliding contact was 0,002675 $\mathrm{dm}^{3} /$ hours. This amount of lubricant is sufficient for the boundary friction.

\section{Results of the measurements}

The waveforms of the friction force and the temperature are the primary results of the friction test. By means of the Labview software the waveforms are displayed on the screen of the laboratory PC, see fig.4, and the measurements values are saved to the Excel program simultaneously.

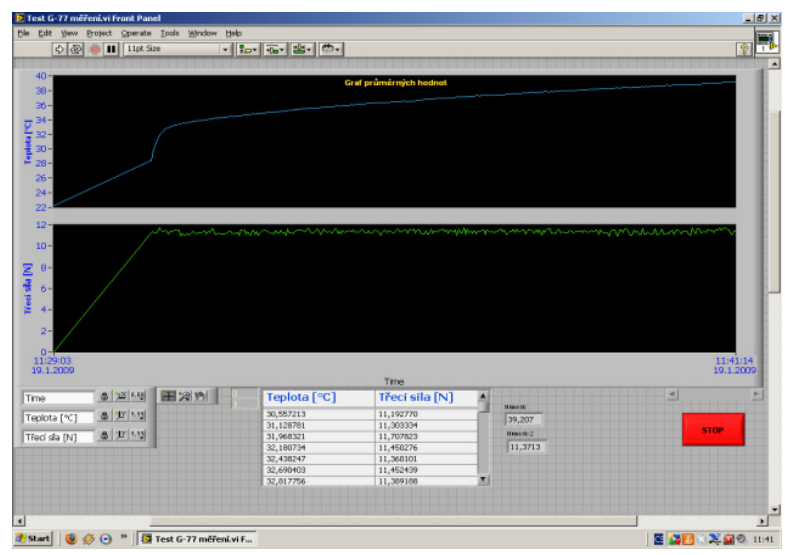

Figure 4: Registration of the friction force and the temperature.

Because of the values saving in the Excel program it is possible to calculate the average values of the friction force. The average friction force was calculated in each of the test steps and the average values were recorded in the graph, see fig.5. The coefficient of friction was calculated from the friction force and the results are recorded in the graph, see fig.6. It is evident that the friction force and the coefficient of friction vary for both tested samples. The varying of the friction values conforms to the materials characteristic properties and to the properties of the used lubricants. The lubricants with properly selected additives are able to create the compact viscous layer between sliding surfaces, which prevents the sliding materials from being in full relative contact. Hu et al. [10] targeted the research on the investigation of the minerals oils and of several types of dispersed nano-particles and their effect on the coefficient of friction and on the wear of the sliding parts. They found several types of nano-particles which decrease the coefficient of friction and the wear very significantly. The similar research with other nano-particles was also done by further authors, for example Liu et al. [11], Batter et al. [12], Zhao et al. [13] and Wu et al. [14]. They mainly studied the influence of the load on the wear in the lubricated environment with different nano-particles additives. 


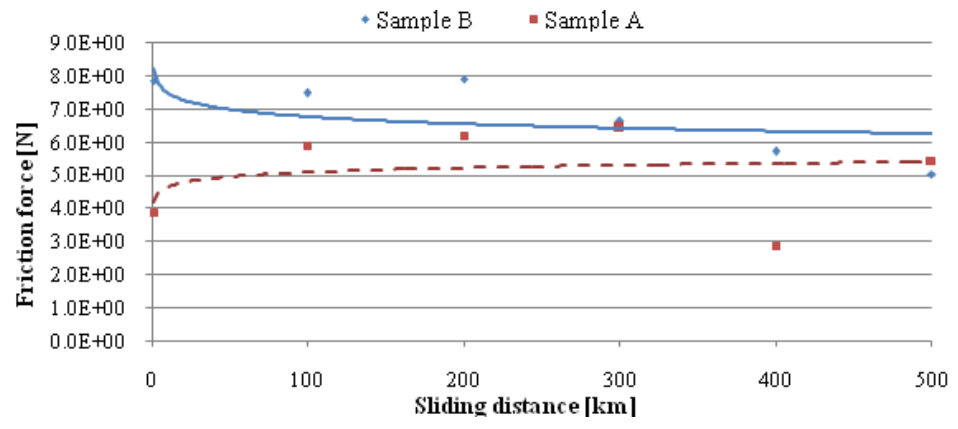

Figure 5: Dependence of the friction force on the sliding distance.

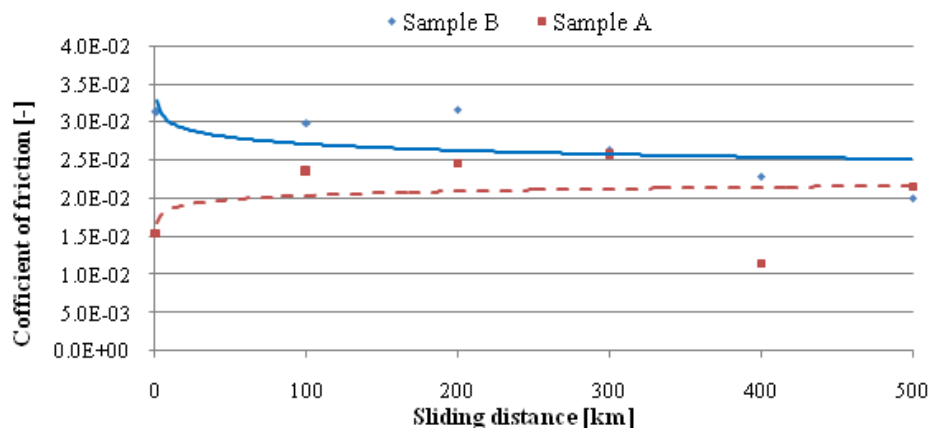

Figure 6: Dependence of the coefficient of friction on the sliding distance.

In fig.7 the coefficient of wear of the "stanit", in fig. 8 the cumulative volume loss of the "stanit" and in fig.9 the actual load of sliding materials couples are recorded. The coefficient of wear decreases markedly. In the first running-up step the coefficient of wear is the highest. Then it decreases and varies for the Sample A in the range 2,1E-06 - 1,1E-05 and for the Sample B in the range $4,5 \mathrm{E}-06-2,2 \mathrm{E}-05$. The values of the actual load of the sliding materials couple decrease as well but the downtrend is smooth in this case. The actual load is dependent on the wear of block sample because of the increasing sliding area between the sliding materials. The larger the contact surface, the lower load presses on the sliding couple. During sliding with the sample B the cumulative wear of the stanit block is visibly higher, see fig.8. It could be ascribed first to the higher roughness of the sample B (NiCr-alloy) and second to the specific properties of NiCr-alloy material. In [15] it is mentioned that the roughness characteristics of the surface have a significant influence on the number of junctions forming, as well as on the ratio of the real area of materials contact to the apparent area of materials contact. Junctions are the points in which the actual contact occurs. The sum of the individual contact areas of these junctions is generally called the real area of the contact. Because of that, during sliding 
122 Surface Effects and Contact Mechanics IX

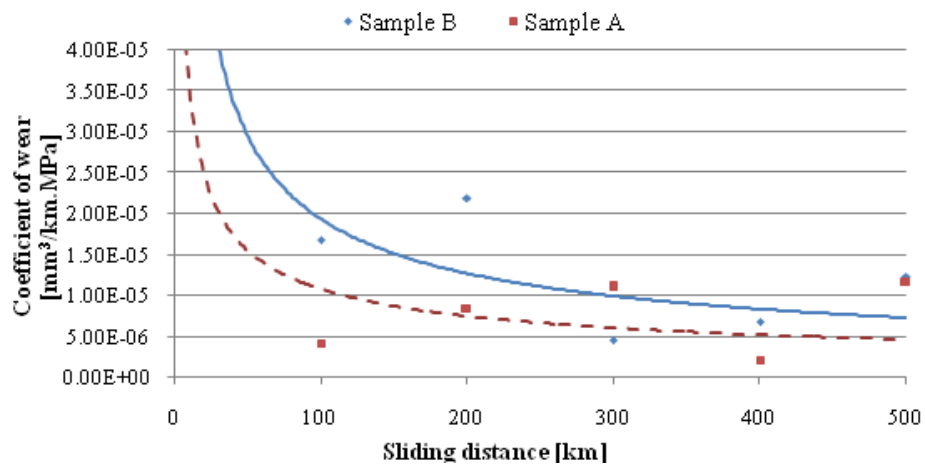

Figure 7: Coefficient of wear of the "stanit".

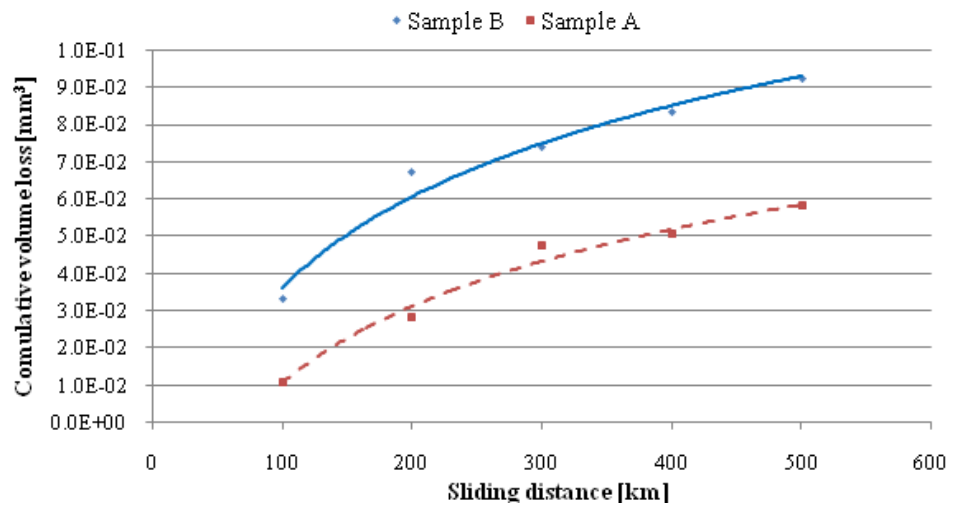

Figure 8: Cumulative volume loss of the "stanit".

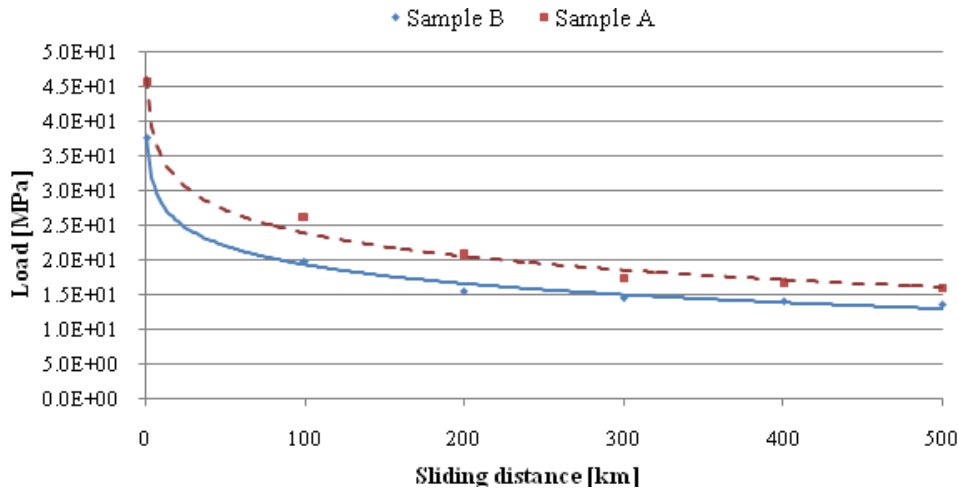

Figure 9: The actual load of the sliding material couples. 


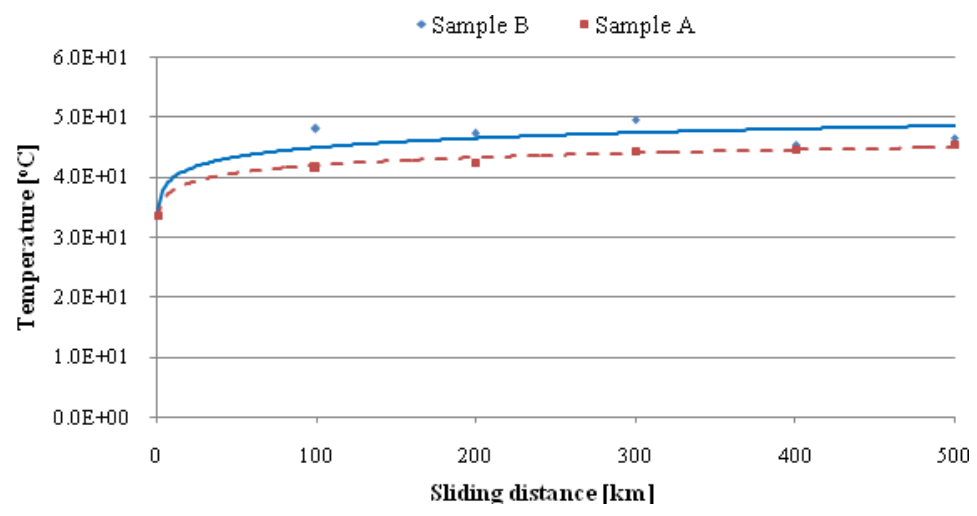

Figure 10: The temperature of the sliding material couples.

using the "block-on-ring" method the surface disturbing of the ring and block sample due to creation of the micro-welded joins between sliding parts may occurs. The wear debris that are then formed detach from the ring and block surface and are carried by the lubricant to the sliding contact. Wear debris released in such away can act then as an abrasive medium and abrade the materials in the sliding contact. Further important factor is the temperature. During the sliding test the temperature in the materials contact increases as the results of the friction. It is possible to record the temperature using the thermocouple, which is placed close to the materials contact. More accurately, the thermocouple is placed in the slight hole in the block sample. The hole is drilled to the deep of two millimeters and it is placed approximately in one millimeter under the sliding surface. The results of the temperature registration are recorded in fig.10. The temperature was identical for both sliding parts and its increasing was very slow.

\section{Conclusion}

The main aim of this paper was to introduce the "block-on-ring" tribology test, which is used in ŠKODA VÝZKUM Ltd, Pilsen CZ. The apparatus for this sliding test was designed in accordance with the ASTMG-77 Standard [4]. The found-out results was showed that using the "block-on-ring" test the friction force, the dynamic coefficient of friction, the temperature in the contact area, the actual load, the coefficient of wear and the cumulative volume loss of the block sample can be recorded and measured. The friction force is recorded using the strain gauge dynamometer and using the Labview software the waveform can be displayed on the PC screen. The sliding distance and the load can be arbitrarily changed. Using the block-on-ring test it is possible to bring the laboratory condition nearer to the real practical conditions and applications because of the possibility of using any fluid lubricants, loads and test durations. 


\section{Acknowledgement}

This paper was prepared thanks to the project of Czech Ministry of Education, Youth and Sports no. MSM4771868401.

\section{References}

[1] Bhushan, B., Introduction to tribology, published by John Wiley and Sons, New York, pp. 207-209 and pp. 544-557, 2002

[2] Vocel, M., Dufek, V. et al., Friction and wear of machine parts, SNTL publisher of technical literature, Praha, pp. 28-30, 1976

[3] ASTM G99 - 05, Standard Test Method for Wear Testing with a Pin-onDisk Apparatus, ASTM International, West Conshohocken, PA, www.astm.org

[4] ASTM G77 - 05, Standard Test Method for Ranking Resistance of Materials to Sliding Wear Using Block-on-Ring Wear Test, ASTM International, West Conshohocken, PA, www.astm.org

[5] ASTM D5183-95(1999)e1, Standard Test Method for Determination of the Coefficient of Friction of Lubricants Using the Four-Ball Wear Test Machine, ASTM International, West Conshohocken, PA, www.astm.org

[6] ASTM D4172-94(2004), Standard Test Method for Wear Preventive Characteristics of Lubricating Fluid (Four-Ball Method), ASTM International, West Conshohocken, PA, www.astm.org

[7] Kašparová, M, Evaluation of friction properties of steel materials and of thermal sprayed coatings together with stanit tin-babbitt counterpart, internal report of ŠKODA VÝZKUM Ltd., 2006

[8] Kašparová, M, Methodology of materials friction properties measured on VRS-3 apparatus using "Block-on-Ring" method, internal report of ŠKODA VÝZKUM Ltd., 2008

[9] Zahálka, F., Apparatus for evaluation of sliding properties, internal report of ŠKODA VÝZKUM Ltd., 2005

[10] Hu, Z.S., Dong, J.X., Chen, G.X. \& He, J.Z., Preparation and tribological properties of nanoparticle lanthanum borate, Wear, 243(1-2), pp. 43-47, 2000

[11] Liu, G., Li, X., Lu, N. \& Fan, R., Enhancing AW/EP property of lubricant oil by adding nano Al/Sn particles, Tribology Letters, 18(1), pp. 85-90, 2004

[12] Battez, A.H., Rico, J.E.F., Arias, A.N., Rodriguez, J.L.V., Rodriguez, R.Ch. \& Fenandez, J.M.D., The tribological behavior of $\mathrm{ZnO}$ nanoparticles as an additive to PAO6, Wear, 261(3-4), pp. 256-263, 2006

[13] Zhao, Y., Zhang, Z. \& Dank, H., A simple way to prepare bismuth nanoparticles, Materials Letters, 58(5), pp. 790-793, 2004

[14] Wu, Y.Y., Tsui, W.C. \& Liu, T.C., Experimental analysis of tribological properties of lubricating oils with nanoparticle additives, Wear, 262(7-8), pp. 819-825, 2007

[15] Bayer, R.G, Mechanical wear prediction and prevention, published by Marcel Dekker, INC., New York, pp. 11-20, 1994 